\title{
correspondence
}

\section{Greek universities}

SIR,-I would like to respond to some of the remarks of Dr Pantelouris on Greek universities (2 February, page 395).

We select students by written examination and everyone with 12 years schooling is eligible. The applicants $(80,000)$ are almost all of those who have finished high school, regardless of their marks, as every father wants to see his child in university. About 15,000 get to university and another 15,000 to vocational colleges. Dr Pantelouris excludes educational colleges for elementary school teachers. About $40 \%$ of high school graduates get into higher education. This number compares very well with other countries. $85 \%$ of the successful applicants pass their entrance exams first time. Tutoring is necessary for students with low marks, but not for the better students. Unfortunately many worry and unnecessarily attend tutoring classes.

Some parents want to see their children enter a university so much that they send their children to Italy, although many return without a degree. This is a social problem, as we do have a great number of students who study abroad, receive a degree and then return expecting a life time job. It is hoped that the reforms in secondary education (presently underway) will meet this problem.

"Lectures are formal and ex-cathedra" says Dr Pantelouris. As far as I know lectures are formal in all universities. I think your correspondent does not read books on education. Research done in the US informs us that "student and faculty performance-whether in interdisciplinary and team courses, student-centred curriculum, writtenevaluation grading or any other structure - proved to be much the same in each programme examined" (A. Levin and J. Weingart, Reform of Undergraduate Education, Jossey-Bass, 1973). Therefore the criticism of Dr Pantelouris is not valid. However, our students do participate in class discussions and seminars. We follow the progress of the means and methods of the teaching and we try to apply them.

Since 1975 every one of our staff who holds a Ph.D. has the right to teach, and it is up to the faculty to decide who will teach what. Here, Dr Pantelouris misrepresents the case. The law obliges the full professor to teach the main course and leaves other courses to be taught by the young professors. So the law protects the quality of teaching and also avoids mistakes already made in other countries. Dr Pantelouris writes that there is one full professor per unit. As far as I know, the same holds for British universities. He then goes on to speak about "the rest of the staff" who have just a first degree It is a mistake to consider them "staff", as they are students working for their Ph.D. degree and are selected as demonstrators. For this purpose they take an assistantship lasting six years, possibly nine. Some universities consider them as instructors. He then continues "there is nothing comparable to the British $10: 1$ student-staff ratio. No average figure can be given, but however calculated, the ratio would be several times higher'. I have just calculated that for our school it is $5: 1$.

Dr Pantelouris thinks that our internal Ph.D. degree is granted on the discretion of the professor and not on the research ability of the candidates. This is quite wrong as it is granted by the faculty of the particular school, where the candidate has to defend the thesis.

His remarks on bureaucracy are correct. However this is a problem for universities all over Europe; some are better and some worse than we are. Dr Pantelouris offers advice on what we have to reform. Theoretical knowledge is not enough for giving advice. Living and experiencing are important factors for offering constructive criticism and to avoid destruction of that which stands correct. What is good for the Greek universities, is not easily determined. There must be careful investigation and research work before anybody tears down the existing system.

Dr Pantelouris should know that attempts at reform, however stimulating and numerous and creative and hopeful, are at loggerheads almost everywhere with traditions-traditional student passivity and traditional university reward systems that extol specialisation and concentration.

Aristotelian University, G. A. Mourkides

Thessaloniki, Greece

\section{Conference ethics}

SiR,-In our letter (16 February, page 605), we described our unsuccessful attempt to attend the Fourth International Meeting on Ferroelectricity held in Leningrad 18-23 September 1977. The response of I. S. Zheludev (20 April, page 666) is of interest and deserves a reply.

First, Zheludev claims that had Havlin merely applied to the Soviet Embassy in Rome, he would have found his visa waiting for him. The only formal response by the Soviet organising committee to all of our letters was sent to the

International Union of Pure and Applied Physics (IUPAP). In early July 1977, the Secretary of the Israel Physical Society, acting on Havlin's behalf, received the following cable from Larkin Kerwin, Secretary General of IUPAP: "I have just received from Leningrad following telegram: 'Professor Havlin's paper is included in the meeting programme. $\mathrm{He}$ should apply for a visa at Intourist or to a firm acting on its behalf in any country ....". On 9 August, Havlin applied for a visa at the Paris office of Intourist. Not only was Rome never mentioned in his eight futile visits to Intourist and to the Soviet Embassy, but he was repeatedly assured that the Soviet Embassy in Paris would issue the visa imminently. This was the case until 9 September when an official in the Embassy told Havlin that there was no chance that he would receive a visa. These facts should be contrasted with the picture presented by Zheludev.

Second, Zheludev raised the possibility that ". . . we could judge the fact that just two scientists tried to participate instead of the four we were informed of, as an additional difficulty created intentionally." Besides ourselves, Dr Lucien Benguigui of the Technion and Dr Yosef Yeshurun of Bar-Ilan University wrote numerous times to the Organising Committee requesting information regarding attendance at the meeting. When they received no replies, they abandoned further attempts to attend. To imply that we were attempting to "create difficulties" by having these individuals express interest in attendance and then failing to appear in Rome or Vienna to collect visas for which they had not applied or been informed of, is

preposterous.

Third, Zheludev complained that we publicised the incident before clarifying details. We have already mentioned that every one of our many letters to the organising committee seeking to clarify matters went unanswered (with the sole exception of the cable to IUPAP). Only after our letter was submitted to Nature, with copies to several international bodies, did the organising committee see fit to respond, both with Zheludev's letter tu Nature and a copy sent directly to us in Israel by normal mail service.

In conclusion, we re-emphasise the profound need for the recommendations which we proposed in our letter of 16 February. The issue is simple: hosting an international conference means fully accepting the responsibility for insuring the possibility of attendance by scientists from all countries. This right must be strictly guaranteed for Israeli scientists as it should be guaranteed for scientists from all other countries. Yours faithfully,

$$
\text { SIDNEY B. LANG }
$$

Ben Gurion University of the Negev Beer Sheva, Israel

Shlomo Havlin

Bar-Ilan University

Ramat Gan, Israel

SIR,-I would like to let you know my position concerning the Cancer Congress in Buenos Aires.

Whilst there are certain people who will go to this congress without restriction, there are others who propose to boycott it and will do so.

I wrote to the Chief of State of Argentina requesting an audience in order to present him with the list of those ccientists of whom we have no news, making this audience the condition for my coming to Buenos Aires.

Since this audience was refused, I wish to let you know that I will not go to Argentina. I consider that this flat refusal gives weight to the argument of those people planning to boycott the meeting. Yours faithfully, Georges Mathé

Institut de Cancérologie et d'Immunogénétique. Villejuif, France 